\title{
Authentic leadership, organisational citizenship behaviour and intention to leave: The role of psychological capital
}

\begin{tabular}{|c|c|}
\hline \multicolumn{2}{|c|}{ 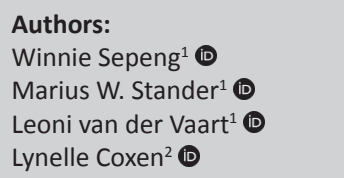 } \\
\hline \multicolumn{2}{|c|}{$\begin{array}{l}\text { Affiliations: } \\
{ }^{1} \text { School of Industrial } \\
\text { Psychology and Human } \\
\text { Resource Management, } \\
\text { Economic and Management } \\
\text { Sciences, North-West } \\
\text { University, Vanderbijlpark, } \\
\text { South Africa }\end{array}$} \\
\hline \multicolumn{2}{|c|}{$\begin{array}{l}\text { Optentia Research Focus } \\
\text { Area, Department of } \\
\text { Industrial Psychology and } \\
\text { Human Resource } \\
\text { Management, North-West } \\
\text { University, Vanderbijlpark, } \\
\text { South Africa }\end{array}$} \\
\hline \multicolumn{2}{|c|}{$\begin{array}{l}\text { Corresponding author: } \\
\text { Lynelle Coxen, } \\
\text { lynelle.coxen@nwu.ac.za }\end{array}$} \\
\hline \multicolumn{2}{|c|}{$\begin{array}{l}\text { Received: } 02 \text { Apr. } 2020 \\
\text { Accepted: } 05 \text { Aug. } 2020 \\
\text { Published: } 23 \text { Oct. } 2020\end{array}$} \\
\hline \multicolumn{2}{|c|}{$\begin{array}{l}\text { How to cite this article: } \\
\text { Sepeng, W., Stander, M.W., } \\
\text { Van der Vaar, L. \& Coxen, L. } \\
\text { (2020). Authentic leadership, } \\
\text { organisational citizenship } \\
\text { behaviour and intention to } \\
\text { leave: The role of psychological } \\
\text { capital. SA Journal of Industrial } \\
\text { Psychology/SA Tydskrif vir } \\
\text { Bedryfsielkunde, 46(0), a1802. } \\
\text { https://doi.org/10.4102/sajip. } \\
\text { v46i0.1802 }\end{array}$} \\
\hline \multicolumn{2}{|c|}{$\begin{array}{l}\text { Copyright: } \\
\text { @ 2020. The Authors. } \\
\text { Licensee: AOSIS. This work } \\
\text { is licensed under the } \\
\text { Creative Commons } \\
\text { Attribution License. }\end{array}$} \\
\hline \multirow[b]{2}{*}{ 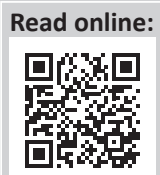 } & \\
\hline & $\begin{array}{l}\text { Scan this QR } \\
\text { code with your } \\
\text { smart phone or } \\
\text { mobile device } \\
\text { to read online. }\end{array}$ \\
\hline
\end{tabular}

Orientation: The orientation of the study was towards psychological capital (PsyCap) as a mediator of the influence authentic leadership (AL) has on organisational citizenship behaviour (OCB) and intention to leave.

Research purpose: This study aimed to investigate the influence of AL on OCB and intention to leave through PsyCap amongst public healthcare employees in South Africa.

Motivation for the study: South African public healthcare needs effective leadership that is value based, transparent, supportive and exemplary in behaviour to be efficient and to provide quality service. By exploring the impact of AL and the process through which such a leader influences followers, the study sought to demonstrate that AL may be effective in achieving valued outcomes in the healthcare sector.

Research approach/design and method: A quantitative, non-experimental, cross-sectional survey was used. A sample of 633 public healthcare employees was included in the study. Measuring instruments included the Authentic Leadership Inventory, a shortened version of the Psychological Capital Questionnaire, Organisational Citizenship Behaviour Scale and the PSYCONES' Intention to Leave Scale. Structural equation modelling was performed to evaluate the hypothesised measurement and structural models by using Mplus.

Main findings: Results indicated that employees' perceptions of their leaders as authentic has an effect on OCB and intention to leave through PsyCap.

Practical/managerial implications: Organisations should implement leadership development programmes that are relationally focussed and should strive to develop employees' PsyCap.

Contribution/value-add: Providing more insight into the influence of authentic leadership on follower organisational citizenship behaviour and intent to leave as well as the role that psychological capital plays in these relationships.

Keywords: authentic leadership; psychological capital; organisational citizenship behaviour; intention to leave; public healthcare.

\section{Introduction}

The Coronavirus disease 2019 (COVID-19) pandemic and its associated health, social and economic consequences placed a renewed focus on healthcare. Although the South African Department of Health (DoH) has set out to improve the status of public healthcare services (Gilson \& Daire, 2011; World Health Organization [WHO], 2013), healthcare institutions remain hampered by inequitable distribution of resources (Health Systems Trust, 2018). In addition to a lack of resources, public healthcare employees are burdened with staff shortages, high workloads and long working hours (Health Systems Trust, 2018; Maphumulo \& Bhengu, 2019), even more so during pandemics. These burdens result from high turnover rates in an overstretched public healthcare sector (Lee, Chiang, \& Kuo, 2019; Trinchero, Borgonovi, \& Farr-Wharton, 2014), which may threaten both the quality of healthcare services (Lee et al., 2019) and the achievement of the DoH's goals. Despite the challenges encountered in this sector, public healthcare employees are expected to 'go the extra mile'.

Resources, both in the workplace and within the individual, may help public healthcare employees deal with the challenges in their work environment and perform optimally (Van Veldhoven et al., 2020). Leadership, as a job resource, is regarded as one of the main building blocks of an efficient health system (Shisana, 2018). More specifically, authentic leadership (AL) has the potential to 
influence public healthcare employees' behaviours positively (see Alilyyani, Wong, \& Cummings, 2018; Malila, Lunkka, \& Suhohen, 2018 for reviews). Leaders who are transparent about their intentions, who are value based and who lead others towards achieving organisational goals through their exemplary behaviour are authentic leaders (Avolio \& Walumbwa, 2014). Ineffective leadership has been a prevailing problem in South African public healthcare (Doherty, Gilson, \& Shung-King, 2018), and public healthcare employees may benefit from having leaders who are genuine, who are not influenced by external pressures and who motivate subordinates to perform.

Job resources also have the potential to activate personal resources (Van Veldhoven et al., 2020). One such personal resource, psychological capital (PsyCap), is of particular importance because it can assist healthcare employees in reaching performance outcomes (Laschinger \& Fida, 2014a; Youssef-Morgan \& Petersen, 2019), do more than what is expected (Beal, Stavros, \& Cole, 2013) and stay with the organisation (Çelik, 2018). Kim, Kim, Newman, Ferris and Perrewé (2019, p. 110) conceptualise PsyCap as 'the development of the actual self into the possible self' and postulate that synergy between human, social and PsyCap is central for actualising human potential in the present workplace. Public healthcare services can benefit from employees engaging in organisational citizenship behaviours (OCBs), as these behaviours encourage employees to do more with fewer resources (Koberg, Boss, Goodman, Boss, \& Monsen, 2005).

Besides leadership and personal resources, employees' attitudes towards their work also matter for performance (Avey, Reichard, Luthans, \& Mhatre, 2011). One particular attitude of interest is their intention to leave (ITL). Intention to leave refers to an employee's intention to leave the organisation or job as for a variety of reasons (De Simone, Planta, \& Cicotto, 2018). If employees display high levels of PsyCap, they can persevere in a challenging work environment, reducing their intention to leave the organisation (Gupta \& Shaheen, 2017; Hayes et al., 2012).

Employees can thus draw on their psychological capacities (i.e., PsyCap) to enhance positive outcomes such as OCB (Beal et al., 2013) and to minimise negative outcomes such as ITL (Fallatah, Laschinger, \& Read, 2017; Laschinger et al., 2016). However, leadership is also important as authentic leaders positively influence followers' PsyCap (Amunkete \& Rothmann, 2015).

A review of AL studies highlights two limitations: studies are limited in both number and scope (Alilyyani et al., 2018; Malila et al., 2018). Only two studies (i.e. Coxen, Van der Vaart, \& Stander, 2016; Stander, De Beer, \& Stander, 2015) were conducted in the South African context, but neither focussed on the (in)direct role of AL on positive and negative employee outcomes (i.e. OCB and ITL) through PsyCap. This is unfortunate, not only because of the assumed importance of AL, PsyCap, OCB and low levels of ITL in an already constrained system, but also because results from studies in other contexts cannot be extrapolated haphazardly.

Recent literature indicates that job resources may not be equally beneficial for all, and more research is needed to understand when, why and for whom these resources may be helpful (Van Veldhoven et al., 2020). Existing literature also indicates that findings relating to the outcomes of PsyCap are not necessarily consistent across contexts and that it may be more influential in the United States of America than in other countries (Luthans \& Youssef-Morgan, 2017). Hence, more information is needed regarding the impact of authentic leaders on followers' OCB and ITL as well as the mechanisms through which AL exerts its influence. The current study aimed to fill this gap by investigating the influence of AL on OCB and ITL and the role that PsyCap plays in these relationships.

\section{Literature review Authentic leadership}

The AL framework draws from the concept of authenticity (Avolio \& Gardner, 2005). Authenticity - as derived from an ancient Greek aphorism - refers to knowing the self and being true to the self (Avolio \& Gardner, 2005). In this study, AL was conceptualised as (Walumbwa, Avolio, Gardner, Wernsing, \& Peterson, 2008):

$[A]$ pattern of leader behaviour that draws upon and promotes both positive psychological capacities and positive ethical climate, to foster greater self-awareness, an internalised moral perspective, balanced processing of information, and relational transparency on the part of the leaders working with followers, fostering positive self-development. (p. 94)

Authentic leadership is a higher-order construct that consists of four lower-order dimensions. Balanced processing constitutes a leader's objectivity when analysing information for decision-making (Walumbwa et al., 2008), whereas possessing an internalised moral perspective is regulating one's thoughts and actions through the guidance of one's moral standards and values against other external factors (Neider \& Schriesheim, 2011). Relational transparency relates to a leader's openness and transparency during interactions with others (Avolio \& Gardner, 2005). Finally, self-awareness refers to the self-knowledge of leaders and the extent to which they are aware of their characteristics (including strengths and areas of development) (Neider \& Schriesheim, 2011; Walumbwa et al., 2008). In the current study, the extent to which leaders display AL behaviours was measured from the subordinates' perspectives. In this study, a follower is regarded as the authentic leader's subordinate.

\section{Authentic leadership and psychological capital}

Authentic leaders have a significant influence on their followers' PsyCap levels (Amunkete \& Rothmann, 2015; Wu \& Nguyen, 2019). Derived from positive organisational behaviour (POB; Luthans, 2002), PsyCap concerns 'who you are' (the actual self) and 'who you are becoming' (your possible self) 
(Luthans, Luthans, \& Luthans, 2004). Positive organisational behaviour analyses and applies human strengths and psychological capacities that meet the criteria of a nomological network because they are measurable, developable and can be managed for performance improvement (Luthans, 2002).

Psychological capital refers to (Luthans, Avolio, Avey, \& Norman, 2007):
... an individual's positive psychological state of development characterised by (1) having the confidence to take on and put in the necessary effort to succeed at challenging tasks (self-efficacy); (2) making a positive attribution about succeeding now and in the future (optimism); (3) persevering toward goals, and when necessary, redirecting paths to goals in order to succeed (hope); and (4) when beset by problems and adversity, sustaining and bouncing back and even beyond (resiliency) to attain success. (p. 10)

These four capacities are conceptually distinct from one another, state-like and work synergistically to facilitate positive outcomes (Luthans et al., 2007; Luthans \& YoussefMorgan, 2017).

In their early development of AL, Luthans and Avolio (2003) identified that PsyCap acts as a personal resource for the authentic leader. Therefore, authentic leaders draw from their own personal resources to contribute to their followers' PsyCap (Wang, Sui, Luthans, Wang, \& Wu, 2014), allowing for positive outcomes (Luthans et al., 2007; Luthans \& Avolio, 2003). For instance, an authentic leader is able to encourage open collaborative relationships that provide feedback and input for growth, providing followers with the confidence to bounce back from setbacks and improve on their work and the ability to keep a positive outlook and create alternative options in reaching their goals (Luthans, Youssef-Morgan, \& Avolio, 2015). Empirical research supports AL's positive association with followers' PsyCap (Alilyyani et al., 2018; Amunkete \& Rothmann, 2015; Du Plessis, 2014; Malila et al., 2018):

H1: Perceived AL associates positively with follower PsyCap.

\section{Authentic leadership and organisational citizenship behaviour}

Organisational citizenship behavior became relevant across diverse industries and organisations as a result of employees being required to do more with fewer resources (Perreira \& Berta, 2016; Podsakoff, Podsakoff, Mackenzie, Maynes, \& Spoelma, 2014). Daniel Katz identified three types of behaviours that can contribute to the effectiveness of the organisation (Selamat, Nordin, \& Fook, 2017). The first behaviour is that people must enter and be part of a system where they remain in the system; the second behaviour requires people to legitimately carry out their in-role duties; and the third behaviour involves employees going beyond their expected roles in carrying out their work innovatively and spontaneously to achieve the organisational objectives (Bolon, 1997; Selamat et al., 2017). The latter behaviour led to the establishment of OCB (Smith, Organ, \& Near, 1983).

Organ (1988, p. 4) defined OCB as 'individual behaviours that are discretionary, not directly or explicitly recognised by the formal reward system and in the end promotes the functioning of the organisation'. He later refined this definition to 'contributions to the maintenance and enhancement of the social and psychological context that supports task performance' (Organ, 1997, p. 91). According to Barrett (2018), OCB refers to behaviour: (1) that goes beyond formal work requirements, (2) that is spontaneous and not enforced by an organisation and (3) that is voluntarily performed. In this study, OCB is conceptualised as (1) employees' willingness to assist co-workers by going beyond what is expected (interpersonal orientation) and (2) employees' willingness to exert extra effort to help the organisation (organisational orientation) (Rothmann, 2010).

These two dimensions of OCB are aligned to Smith et al.'s (1983) descriptions of altruism and generalised compliance. Altruism refers to behaviour that seeks to help a specific person, such as voluntarily assisting with tasks that are not required, showing courtesy to a colleague by helping when they are absent or going out of one's way to include new colleagues into the group (Smith et al., 1983). Generalised compliance refers to impersonal behaviours of compliance to an organisation's norm of what constitutes a good employee, for instance, being punctual, offering ideas that are good for the organisation or defending the organisation (Smith et al., 1983).

An authentic leader's influence on follower outcomes is an integral part of the AL theoretical framework (Walumbwa et al., 2008). Meta-analytical studies posit that perceived AL accounts for variance in follower OCB, based on the leader's key behaviours that influence followers to identify themselves with the leader, which in turn elicits higher citizenship behaviours (Valsania, Léon, Alosono, \& Cantisano, 2012; Walumbwa et al., 2008). The variance in follower OCB, explained by AL, is expounded by the increased levels of trust, hope, positive emotions and optimism amongst followers (Ilies, Morgeson, \& Nahrgang, 2005). Authentic leaders can empower followers to make positive changes by improving on their job performance and going beyond expectations (Alilyyani et al., 2018; Malila et al., 2018). In sum, AL is a critical factor in eliciting the OCB of followers (Valsania et al., 2012):

H2: Perceived AL associates positively with follower OCB.

\section{Authentic leadership and intention to leave}

Intention to leave is a conscious and well-thought-through decision to leave the organisation (Tett \& Meyer, 1993), and it can be described as the last stage before the employee does leave the organisation (Griffeth, Hom, \& Gaertner, 2000; Winterton, 2004). An individual on this level is either in a preparatory stage, where they are gathering available information about job opportunities, or they are actively searching for a job by sending out résumés (Griffeth et al., 2000). Research on turnover intention sought to discover predictors of ITL before the employee quits (Podsakoff, LePine, \& LePine, 2007; Ritter, 2011). When evaluating the 
determinants of ITL, one can distinguish between 'push factors' (i.e. those that will lead to employees leaving) and 'pull factors' (i.e. those encouraging employees to stay) (Sasso et al., 2019). Leadership and participation in hospital matters are important 'pull factors' (Sasso et al., 2019), as supportive leadership buffers job dissatisfaction experienced by employees (Laschinger \& Fida, 2014b).

Authentic leaders help build healthy work environments through their availability and exemplary behaviours that are conducive to positive employee outcomes, for example, lowered intentions to leave the organisation (Blake, Leach, Robbins, Pike, \& Needleman, 2013; Laschinger \& Fida, 2014b). Empirical studies support the negative relations between AL and employees' ITL (Fallatah et al., 2017; Laschinger et al., 2016; Munyaka, Boshoff, Pietersen, \& Snelgaret, 2017):

H3: Perceived AL associates positively with follower ITL.

\section{Psychological capital, organisational citizenship behaviour and intention to leave}

Despite the importance of PsyCap in its own right, the organisational outcomes of PsyCap also matter. Corporate decision-makers need evidence-based information regarding the impact of PsyCap on the bottom line as well as on performance(Luthans \& Youssef-Morgan, 2017). Consequently, OCB (as a performance indicator) and ITL (which potentially impacts on performance and the bottom line) are essential outcome measures. Previous studies indicated that PsyCap has significant positive effects on individual, group and organisational outcomes (Du Plessis \& Boshoff, 2018; Luthans \& Youssef-Morgan, 2017). More specifically, these studies indicate that PsyCap acts as a positive resource to enhance OCB (Newman, Ucbasaran, Zhu, \& Hirst, 2014; Wang et al., 2014; Wu \& Nguyen, 2019) and intention to stay with the organisation (Dhiman \& Arora, 2018; Maloney, Boxall, Parsons, \& Cheung, 2018):

H4: PsyCap associates positively with OCB.

H5: PsyCap associates negatively with ITL.

\section{The indirect effects of psychological capital}

Using the job demands-resources (JD-R) theory, PsyCap is posited as a mechanism through which AL has an impact on OCB and ITL. The JD-R theory states that each job consists of job resources that play a motivational role in ensuring performance (Bakker \& Demerouti, 2014, 2017). The JD-R theory also postulates that individuals possess intrapersonal resources that enable them to influence the environment (Hobfoll, Halbesleben, Neveu, \& Westman, 2018) and that job resources activate personal resources (Van Veldhoven et al., 2020). Consequently, AL is seen as a job resource that can directly foster discretionary behaviours (i.e. OCB) whilst lowering employees' ITL. It can also indirectly do so by activating personal resources (i.e. PsyCap) that help employees display positive discretionary behaviours and attitudes towards the organisation (Alilyyani et al., 2018; Wang et al., 2014). This is likely because PsyCap implies that

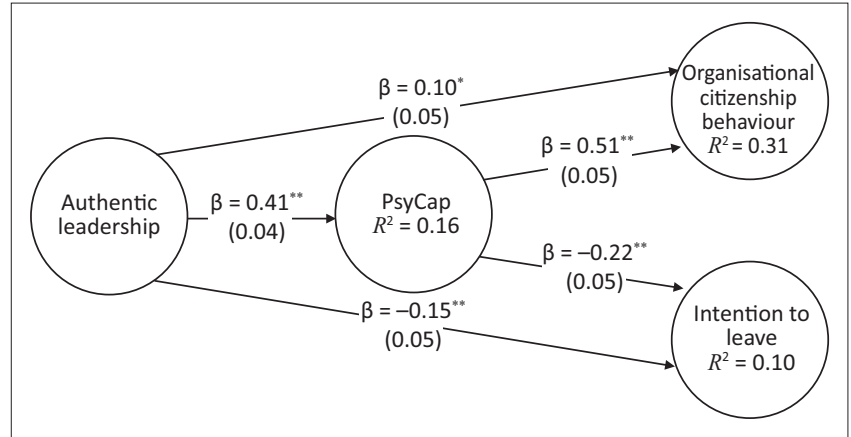

PsyCap, psychological capital.

FIGURE 1: The structural model of perceived authentic leadership, PsyCap, organisational citizenship behaviour and intention to leave.

individuals have the perception that they can influence their environments and that they can engage intentionally and autonomously when pursuing set goals. These individuals can also make positive attributions about future success even when confronted by challenges (Luthans \& Youssef-Morgan, 2017). Empirical research supports the mediating properties of PsyCap. For example, PsyCap mediates the relationship between AL and employee creativity (Rego, Sousa, Marques, \& Cunha, 2012) and between AL, commitment and job performance (Woolley, Caza, \& Levy, 2014):

H6: Perceived AL has an indirect effect on OCB through PsyCap.

H7: Perceived AL has an indirect effect on ITL through PsyCap.

Based on the above discussions, the hypothesised model can be depicted as follows (Figure 1).

\section{Research design Research approach}

A quantitative, non-experimental, cross-sectional approach was used (Gravetter \& Forzano, 2012) to explore relationships between the AL, PsyCap, OCB and ITL. Cross-sectional designs are often used to determine whether variables are related before investing resources in longitudinal studies (Spector, 2019).

\section{Research method \\ Research participants}

Surveys were disseminated to employees employed at hospitals and clinics in the Sedibeng District of the Gauteng Province. A total of 2000 employees were targeted by using non-probability convenient sampling, and 633 usable surveys were obtained. The majority of the participants were Black (87.9\%), Sesotho-speaking (44\%) females (79.6\%). More than one-third of the participants were in possession of a diploma. Almost half of the employees had been employed in the same job for $<5$ years (40.3\%). Lastly, the mean age of the respondents was 42 years (standard deviation $[\mathrm{SD}]=12.27$ ).

\section{Measuring instruments}

Authentic leadership was measured by using the Authentic Leadership Inventory (ALI; Neider \& Schriesheim, 2011) in 
terms of follower (subordinate) perceptions of their leader's self-awareness, balanced processing, relational transparency and moral perspective. The ALI contains 14 items, with selfawareness and relational transparency measured by three items each and balanced processing and moral perspective each measured by four items. Examples of each dimension are: 'my leader describes accurately the way others view his or her abilities' (self-awareness); 'my leader asks for ideas that challenge his or her core beliefs' (balanced processing); 'my leader clearly states what he or she means (relational transparency'); and 'my leader shows consistency between his or her beliefs and actions' (moral perspective). The items were measured on a five-point Likert-type scale ranging from 1 (strongly disagree) to 5 (strongly agree). The ALI showed an acceptable reliability with a Cronbach's alpha coefficient of 0.92 and a McDonald's omega coefficient of 0.93 .

Psychological capital was measured by using the shortened version of the Psychological Capital Questionnaire (PCQ; Avey et al., 2011) in terms of followers' hope, resilience, optimism and self-efficacy. The scale comprises 12 items, and each construct is measured by three items. The items were measured on a six-point Likert-type scale ranging from 1 (strongly disagree) to 6 (strongly agree). Examples of each scale are: 'if I should find myself in a jam at work, I could think of many ways to get out of it' (hope); 'I can get through difficult times at work because I've experienced difficulty before' (resilience); 'I always look on the bright side of things regarding my job' (optimism); and 'I feel confident in representing my work area in meetings with management' (self-efficacy). In this study, the PCQ showed a Cronbach's alpha coefficient of 0.88 and a McDonald's omega coefficient of 0.89 , indicating an acceptable reliability.

Organisational citizenship behaviour was measured by the Organisational Citizenship Behaviour Scale (OCBS; Rothmann, 2010), which consists of two dimensions of OCB (assistance towards the individual and assistance towards the organisation). The questionnaire comprises six items, in which each dimension is measured by three items. The sevenpoint Likert-type response scale ranges from 1 (strongly disagree) to 7 (strongly agree). Examples of the items are: 'I give up time to help co-workers who have work or non-work problems' (behaviour at the individual level) and 'I take action to protect the organisation from potential problems' (behaviour at the organisational level). Both reliability indicators (Cronbach's alpha and McDonald's omega) showed an acceptable reliability of 0.79 .

Intention to leave was measured by the Intention to Leave Scale, derived from the PSYCONES project (Guest, Isaksson, \& De Witte, 2010). The scale contains four items. An example of an item is: 'despite the obligations I have made to this organisation, I want to quit my job as soon as possible'. The items are scored on a five-point Likert-type scale ranging from 1 (strongly disagree) to 5 (strongly agree). This study yielded a Cronbach's alpha coefficient of 0.83 and a McDonald's omega coefficient of 0.72 , which shows an acceptable reliability.

\section{Research procedure and ethical considerations}

The study received ethical clearance from the ethics committee of the relevant university. Arrangements were made with the management of the participatory district hospitals and clinics to conduct the research and to obtain permission from participants. Paper-and-pencil questionnaires, consent forms and information letters were distributed to participants by the gatekeepers of each facility. These documents contained the objectives of the study and explained the voluntary nature of participation. Written informed consent was obtained, and anonymity as well as confidentiality were ensured. Participants could complete the questionnaires at their own pace. Participants were then required to submit the completed questionnaires in a secure box at each facility, whereafter the boxes were collected and kept safe.

\section{Statistical analysis}

Statistical analysis was performed with JASP Team (2019) as well as Mplus 8.4 (Muthén \& Muthén, 1998-2018). Structural equation modelling was used. The first step was to evaluate the factor structure (i.e. construct validity) of the measuring instruments. To achieve this, a confirmatory factor analysis approach was followed in which a measurement model was constructed. The measurement model contained the latent variables (AL, PsyCap, OCB and ITL) with their respective observed indicators (i.e. items) and the relationships between the latent variables. The cut-off values of the effect sizes for correlations (i.e. relationships between the latent variables) in the study ranged from $r=\geq 0.10$ (small effect), $r=\geq 0.30$ (medium effect) to $r \geq 0.50$ (large effect) (Cohen, 1992). The measurement model was used as the basis for the structural model in the second step. In the structural model, regression paths were added to determine whether the independent variables 'predict' the dependent variables (Kline, 2016). Authentic leadership was specified as independent, PsyCap as both independent and dependent and OCB and ITL as dependent variables. The default (i.e. maximum likelihood) estimator was used to estimate the models (Kline, 2016).

In both steps, the models' fit to the data was evaluated by means of the following goodness-of-fit indices (Hu \& Bentler, 1999; Kline, 2016): (1) the chi-square $\left(\chi^{2}\right)$ and its associated degrees of freedom $(d f)$; (2) the standardised root mean square residual (SRMR); (3) the comparative fit index (CFI); (4) the Tucker-Lewis Index (TLI); and (5) the root means square error of approximation (RMSEA) and its associated confidence interval (CI). A non-significant chisquare statistic is considered to indicate a good fit with the sample data (Hu \& Bentler, 1999) but is sensitive to sample size and often not a good indicator of model fit (Wang \& Wang, 2020). For the CFI and TLI indices, values above 0.95 for CFI and TLI are regarded as acceptable (Hu \& Bentler, 1999) but should be treated as guidelines in applied research (West, Taylor, \& Wu, 2012). Wang and Wang (2020) consider 0.90 as an appropriate cut-off value for these two fit indices. For the RMSEA and SRMR indices, values smaller than 0.08 
are accepted (Hu \& Bentler, 1999). McDonald's omega coefficient and Cronbach's alpha coefficient were both used to calculate the internal consistency of the scales, with a cutoff value of 0.70 (Revelle \& Zinbarg, 2009).

Lastly, the procedure for estimating indirect effects on the hypothesised model, as suggested by Hayes (2017), was used. Psychological capital was specified as a mediator in the analysis. Bootstrapping (using 10000 samples), with bias-corrected confidence intervals (CIs), was used to generate more accurate estimations of possible indirect effects than standard methods. The bias-corrected CIs were set at $95 \%$ for all indirect effects. The lower and upper percentiles served as a limit in that if zero was not contained within limits, an indication of the indirect effect was achieved (Hayes, 2017).

\section{Ethical consideration}

This article adheres to the ethical guidelines for research. Ethical clearance was obtained from the North-West University (no. NWU-HS-2014-0143, 10-03-2015).

\section{Results}

\section{Testing the measurement model}

The hypothesised model consisted of four constructs: AL (one latent variable indicated by four manifest indicators or parcels), PsyCap (one latent variable indicated by four manifest indicators or parcels), OCB (latent variable) and ITL (latent variable). Parcels were created by averaging the items (as recommended by Little, Rhemtulla, Gibson, \& Schoemann, 2013) for the four dimensions of AL and PsyCap, respectively. Authentic leadership and PsyCap were modelled as unidimensional in line with previous research (Coxen et al., 2016; Stander et al., 2015) and theory (Luthans et al., 2004). Organisational citizenship behaviours and ITL were modelled in line with theory. The model fitted the data well $\left(\chi^{2}=494.96^{*}\right.$; $d f=129 ;$ RMSEA $=0.07 * \mathrm{CI}$ : [0.06, 0.07]; CFI = 0.93; TLI = 0.92; and SRMR $=0.07$ ) and was used as a basis for the structural model.

The descriptive statistics, reliabilities and correlations are reported in Table 1. All of the scales were reliable, ranging from 0.72 to 0.93 . All the relationships between the variables were statistically significant in the expected directions. Practically significant relationships included AL with PsyCap $(r=0.41$; medium effect), AL with OCB $(r=0.31$; medium

TABLE 1: Descriptive statistics, correlations and reliabilities.

\begin{tabular}{|c|c|c|c|c|c|c|c|}
\hline Variable & M & SD & $\alpha$ & $\Omega$ & 1 & 2 & 3 \\
\hline 1. Authentic leadership & 3.34 & 0.86 & 0.92 & 0.93 & - & - & - \\
\hline 2. PsyCap & 4.52 & 0.82 & 0.88 & 0.89 & $0.41 \dagger * *$ & - & - \\
\hline $\begin{array}{l}\text { 3. Organisational } \\
\text { citizenship behaviour }\end{array}$ & 2.58 & 1.13 & 0.79 & 0.79 & $0.31 \div * * 0$ & $.55+* *$ & - \\
\hline 4. Intention to leave & 3.74 & 1.16 & 0.83 & 0.72 & $-0.24 * *-C$ & $0.28 * *$ & $-0.10 *$ \\
\hline
\end{tabular}

Note: In the table, 1 refers to AL; 2 refers to PsyCap; 3, refers to ITL.

M, mean; SD, standard deviation; $\alpha$, Cronbach's alpha reliability coefficient; $\omega$, McDonald's coefficient omega; PsyCap, psychological capital.

$*, p<0.05 ; * *, p<0.01$

$\dagger, r>0.30$ (medium effect); $\ddagger, r>0.50$ (large effect). effect) and PsyCap with OCB ( $r=0.55$; large effect). Authentic leadership, PsyCap and OCB were statistically related to ITL, but only with a small practical effect: AL $(r=-0.24)$, PsyCap $(r=-0.28)$ and OCB $(r=-0.10)$.

\section{Testing the structural model}

Regression paths between the constructs were added in a structural model with direct and indirect pathways specified. The model fit results were identical to those of the measurement model. The results, as shown in Figure 2, indicate that the estimated path coefficient from $\mathrm{AL}$ to PsyCap $(\beta=0.41, p<0.01)$ was significant. Authentic leadership explained $16 \%$ of the variance in PsyCap (medium effect). Therefore, Hypothesis 1, stating that perceived AL associates positively with PsyCap, was accepted.

The results also indicated that the estimated path coefficients from AL to OCB $(\beta=0.10, p<0.05)$ and ITL $(\beta=-0.15, p<0.01)$ were both significant. Hypothesis 2 , stating that perceived AL associates positively with follower $\mathrm{OCB}$, and Hypothesis 3, stating that perceived AL associates negatively with follower ITL, were accepted. The path coefficient from PsyCap ( $\beta=$ $0.51, p<0.01)$ to OCB was significant. Additionally, the path coefficient from PsyCap $(\beta=-0.22, p<0.01)$ to ITL was also significant. Hypotheses 4 and 5 , stating that PsyCap associates positively with OCB and ITL, were accepted.

\section{Indirect effects of psychological capital}

As indicated in Table 2, the indirect effect from AL to OCB via PsyCap (estimate $=0.21 ; 95 \% \mathrm{CI}: 0.15,0.27$ ) was statistically significant as the CI did not include zero.

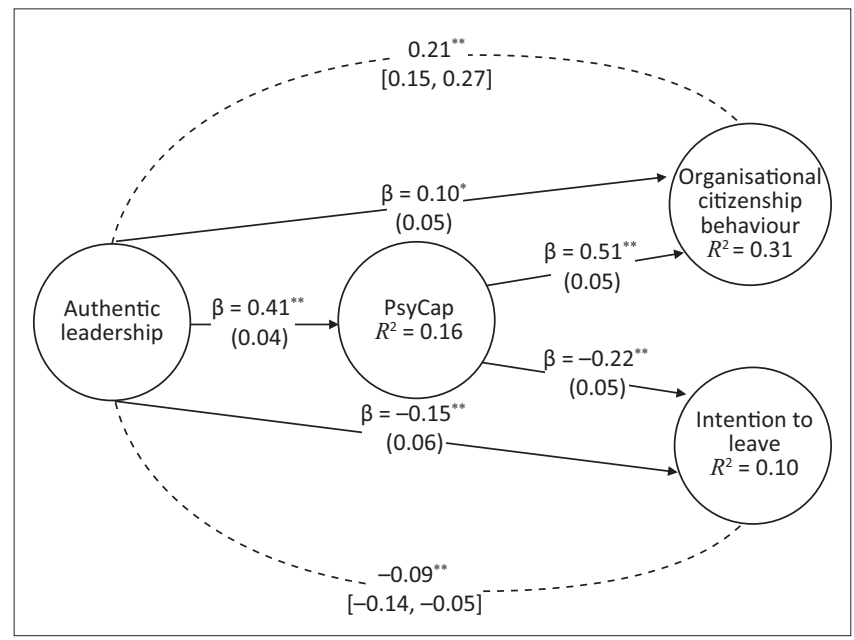

Note: Dashed lines indicate indirect effects (estimates and confidence intervals). PsyCap, psychological capital.

FIGURE 2: The structural model of authentic leadership, PsyCap, organisational citizenship behaviour and intention to leave.

TABLE 2: Indirect effects of authentic leadership via psychological capital.

\begin{tabular}{lccc}
\hline Variable & Estimate & SE & $95 \% \mathbf{C l}$ \\
\hline Organisational citizenship behaviour & $0.21 * *$ & 0.03 & {$[0.15,0.27]$} \\
Intention to leave & $-0.09 * *$ & 0.02 & {$[-0.14,-0.05]$} \\
\hline
\end{tabular}

$\mathrm{Cl}$, confidence interval; $\mathrm{SE}$, standard error.

$* *, p<0.01$. 
Similarly, the indirect effect from AL to ITL via PsyCap (estimate $=-0.09 ; 95 \%$ CI: $-0.14,-0.05$ ) was also statistically significant, with the confidence interval excluding zero. These results support the main aim of the study, namely to establish PsyCap as a mediator in the relationship between $\mathrm{AL}$ and follower outcomes.

Hypotheses 6, stating that AL has an indirect impact on OCB through PsyCap, and 7, stating that AL has an indirect impact on ITL through PsyCap, were accepted.

\section{Discussion}

Public healthcare is the first point of contact for the majority of low- to middle-class citizens in South Africa, which emphasises the importance of these institutions in providing quality care to patients (Doherty et al., 2018; Maphumulo \& Bhengu, 2019). With increasing pressure, there is a call for positive relational leadership that can establish a conducive work environment (Gilson \& Daire, 2011; Kumar, 2013) and for research investigating the mechanisms through which such job resources (e.g. leadership and employee psychological capabilities) operate (Van Veldhoven et al., 2020). Hence, the objective of this study was to investigate the indirect effect of perceived AL on OCB and ITL through the PsyCap of public healthcare employees.

The results of the study show that AL exerts an effect through specific mechanisms. More specially, the results from the current study indicate that PsyCap acts as a mediator through which AL influences followers' behaviours and attitudes positively. Authentic leaders create followers who feel in control and optimistic about autonomously pursuing and achieving goals even in the face of adversity, who, in turn, are prepared to 'go the extra mile' for both co-workers and the organisation, and who wish to remain with the organisation. These findings are in line with empirical studies in healthcare that support the notion that AL precedes the desired follower outcomes via PsyCap (see Alilyyani et al., 2018 for a review).

The current study supports the notion that authentic leaders act as a resource in the public healthcare environment by enhancing followers' personal resources and fostering positive attitudes and behaviour. More specifically, the results show that an authentic leader - one who can develop an open and interactive relationship with subordinates creates self-efficacious, hopeful, resilient and optimistic followers. This finding is in line with the JD-R theory, which postulates that job resources precede personal resources (Bakker \& Demerouti, 2014, 2017), as well as with previous research (Amunkete \& Rothmann, 2015; Du Plessis, 2014; Munyaka, 2012). Similarly, such a leader inspires followers to display altruistic behaviours and to 'go the extra mile' for the organisation. This finding is in line with the social exchange theory that postulates that individuals' interactions are dependent on the actions of those involved in the interaction and, thus, are reciprocal (Blau, 1964). So followers will display positive behaviours in reaction to favourable actions displayed by an authentic leader. This is also in line with previous research (Malila et al., 2018; Shapira-Lishinsky, \& Tsemach, 2014). Authentic leaders, furthermore, act as a 'pull factor', positively influencing those who wish to leave the organisation. This finding also supports existing research (Fallatah et al., 2017; Laschinger et al., 2016).

The results from the current study show that PsyCap has positive effects on employee behaviours. More specifically, self-efficacious, hopeful, resilient and optimistic followers also tend to display more altruistic behaviours towards their co-workers whilst also going beyond what is expected from them by the organisation. From the results of the current study, it seems that believing in one's ability to master tasks (i.e. self-efficacy), persevering and creating pathways towards goals (i.e. hope), having a positive outlook about future success (i.e. optimism) and a perception that one can bounce back from adversity (i.e. resilience) matter for positive follower behaviours. This is in line with the JD-R theory (Bakker \& Demerouti, 2014, 2017) and previous research (Newman et al., 2014; Wang et al., 2014; Wu \& Nguyen, 2019). The results also indicate that self-efficacious, hopeful, resilient and optimistic followers are less inclined to want to leave the organisation. Hence, PsyCap not only enables positive behaviours but also acts as a 'pull factor' to retain employees. Consequently, the results are in line with the JD-R theory (Bakker \& Demerouti, 2014, 2017) and previous research (Dhiman \& Arora, 2018; Maloney et al., 2018).

The present study makes three theoretical contributions. Firstly, the study contributes to the limited research on AL in public healthcare. It does so by illustrating that AL acts as a resource for desirable follower outcomes in the public healthcare sector. Secondly, it contributes to the JD-R literature by illustrating the mechanism (i.e. PsyCap) through which AL exerts its influence, leading to a more nuanced understanding of why a job resource like AL is beneficial. Lastly, it contributes to PsyCap literature by illustrating that it is helpful in a country other than the United States of America.

\section{Implications for practice}

Authentic leadership contributes to the self-efficacy, hope, resilience and optimism of followers. For positive outcomes to be reached, the presence of AL is an important stimulator of employees' personal resources to enable them in their work, which in turn may help them contribute to quality client care (Alilyyani et al., 2018). With this said, AL development should be considered for all managers and supervisors. As ineffective leadership contributes to the current public healthcare crises (Doherty et al., 2018), leadership development is essential. In this regard, coaching and mentoring can play an essential role in developing authentic leaders (Kinsler, 2014; Maldanado, 2013).

Because PsyCap also led to employees exhibiting OCB whilst lowering their ITL, development from the perspective of POB is suggested. In line with this suggestion, Luthans and 
Youssef-Morgan (2017) developed a psychological capital intervention (PCI) model and discussed at length the conditions under which these interventions should be administered for an optimal impact. A typical PCI entails setting goals, generating pathways to achieve these goals, mentally rehearsing pathways and developing plans to overcome envisaged obstacles (Luthans \& Youssef-Morgan, 2017). Human resource practitioners or industrial psychologists in the healthcare industry can initiate AL and PsyCap development initiatives to foster positive employee outcomes (such as OCB and reduced ITL).

\section{Limitations and recommendations for future studies}

The study was cross-sectional, which limited the ability to make causal inferences. Although the hypotheses are in line with theory, a longitudinal approach is encouraged for a confirmation of the predictive effect of $\mathrm{AL}$ on $\mathrm{OCB}$ and the intentions of employees to leave the organisation. A carefully designed longitudinal study (see Spector, 2019 for recommendations) is essential for establishing a mediating effect (Hayes, 2017). Another limitation is attributed to selfreport surveys being the only source of information for the study, as well as the contextual understanding of the variables in the study. These two factors can be the reason for the common method bias (i.e. variance that is attributed to the measurement method instead of the constructs that the measures represent), which can lead to measurement errors (Podsakoff, MacKenzie, Lee, \& Podsakoff, 2003). To address this limitation, future studies could consider obtaining measurements of $\mathrm{AL}$ from respondents other than the subordinate (follower) or from the leader directly. Authentic leadership only explained a certain proportion of the variance in PsyCap; therefore, other antecedents of PsyCap should be explored. Similarly, little variance was explained in ITL, and more research is needed to identify the determinants of ITL, given the importance of the public healthcare sector. Authentic leadership and PsyCap research is at an early stage in the South African context, particularly in the healthcare sector; more research is needed to determine the replicability of the current findings. According to Gilmartin and D'Aunno (2007), the concept of leadership should be explored because the health sector differs from most other sectors. The sample consisted of employees from all departments, and future research could perhaps focus on core frontline staff, such as healthcare professionals. Lastly, the current study did not control for the impact of demographic variables in the model. Although there were no significant differences between different sociodemographic groups (e.g. age, gender, occupation and race) on the latent variables, it is recommended that researchers consider the influence of demographic variables in future studies. It is also recommended that they do so in line with the recommendations by Bernerth and Aguinis (2016).

\section{Conclusion}

Despite its limitations, the study's results indicated that AL contributes positively to desirable follower behaviours and attitudes, both directly and indirectly by fostering follower
PsyCap. This study contributes to the literature by highlighting the value of both AL and PsyCap and does so in an environment where effective leadership is essential. Public healthcare facilities are, therefore, encouraged to develop their leaders into open, transparent, consultative and morally guided individuals.

\section{Acknowledgements}

The authors thank Leon T. de Beer for performing the statistical analysis.

\section{Competing interests}

The authors declare that they have no financial or personal relationships that may have inappropriately influenced them in writing this article.

\section{Author's contributions}

W.S. acted as the primary researcher as this study formed part of her master's research. She shared in the conceptualisation of the article, collection of the data, interpretation of the research results and the writing of the article. M.W.S. and L.v.d.V. acted as supervisor and cosupervisor, respectively. They played an advisory role, assisting in the conceptualisation of the study, collecting data, assisting with the interpretation of the research results and refining the research article. L.C. also assisted in refining the research article and performed the technical editing of the manuscript.

\section{Funding information}

This research received no specific grant from any funding agency in the public, commercial or not-for-profit sectors.

\section{Data availability statement}

Data sharing will be done in line with ethics requirements. The data and syntaxes are the intellectual property of the North-West University and will be provided upon reasonable requests. Contact the authors for more information.

\section{Disclaimer}

The views and opinions expressed in this article are those of the authors and do not necessarily reflect the official policy or position of any affiliated agency of the authors.

\section{References}

Alilyyani, B., Wong, C.A., \& Cummings, G. (2018). Antecedents, mediators, and outcomes of authentic leadership in healthcare: A systematic review. International Journal of Nursing Studies, 83(1), 34-64. https://doi.org/10.1016/j.ijnurstu. 2018.04.001

Amunkete, S., \& Rothmann, S. (2015). Authentic leadership, psychological capital, job satisfaction and intention to leave in state-owned enterprises. Journal of Psychology in Africa, 25(4), 271-281. https://doi.org/10.1080/14330237.2015.10 78082

Avey, J.B., Reichard, R.J., Luthans, F., \& Mhatre, K.H. (2011). Meta-analysis of the impact of positive psychological capital on employee attitudes, behaviors, and performance. Human Resource Development Quarterly, 22(2), 127-152. https:// doi.org/10.1002/hrdq.20070 
Avolio, B.J., \& Gardner, W.L. (2005). Authentic leadership development: Getting to the root of positive forms of leadership. The Leadership Quarterly, 16(3), 315-338. https://doi.org/10.1016/j.leaqua.2005.03.001

Avolio, B.J., \& Walumbwa, F.O. (2014). Authentic leadership theory, research and practice: Steps taken and steps that remain. In D. Day (Ed.), The Oxford handbook of leadership and organizations (pp. 331-356). New York, NY: Oxford University Press.

Bakker, A.B., \& Demerouti, E. (2014). Job demands-resources theory. In C. Cooper \& P. Chen (Eds.), Wellbeing: A complete reference guide (pp. 37-64). Chichester: Wiley-Blackwell.

Bakker, A.B., \& Demerouti, E. (2017). Job demands-resources theory: Taking stock and looking forward. Journal of Occupational Health Psychology, 22(3), 273-285. https://doi.org/10.1037/ocp0000056

Barrett, R. (2018). Influence of self-control, risk-taking, manipulation and integrity on organisational citizenship behaviour. Master's dissertation. Retrieved from https://scholar.sun.ac.za/handle/10019.1/105031

Beal, L., Stavros, J.M., \& Cole, M. (2013). Effect of psychological capital and resistance to change on organisational citizenship behaviour. South African Journal of to change on organisational citizenship behaviour. South African Journo
Industrial Psychology, 39(2), 11. https://doi.org/10.4102/sajip.v39i2.1136

Bernerth, J.B., \& Aguinis, H. (2016). A critical review and best-practice recommendations for control variable usage. Personnel Psychology, 69(1), 229-283. https://doi. org/10.1111/peps.12103

Blake, N., Leach, L.S., Robbins, W., Pike, N., \& Needleman, J. (2013). Health work environments and staff nurse retention: The relationship between communication, collaboration, and leadership in the paediatric intensive care unit. Nursing Administration Quarterly, 37(4), 356-370. https://doi.org/10.1097/ NAQ.0b013e3182a2fa47

Blau, P.M. (1964). Exchange and power in social life. New York, NY: John Wiley \& Sons.

Bolon, D. (1997). Organizational citizenship behaviour among hospital employees: A multidimensional analysis involving job satisfaction and organisationa commitment. Hospital Health Services Administration, 42(2), 221-241.

Çelik, M. (2018). The effect of psychological capital level of employees on workplace stress and employee turnover intention. Innovar: Revista de Ciencias Administrativas y Sociales, 28(68), 67-75. https://doi.org/10.15446/innovar. v28n68.70472

Cohen, J. (1992). A power primer. Psychological Bulletin, 12(1), 155-159. https://doi. org/10.1037/0033-2909.112.1.155

Coxen, L., Van der Vaart, L., \& Stander, M.W. (2016). Authentic leadership and organisational citizenship behaviour in the public health care sector: The role of workplace trust. South African Journal of Industrial Psychology, 42(1), 13. https:// doi.org/10.4102/sajip.v42i1.1364

De Simone, S., Planta, A., \& Cicotto, G. (2018). The role of job satisfaction, work engagement, self-efficacy and agentic capacities on nurses' turnover intention and patient satisfaction. Applied Nursing Research, 39(1), 130-140. https://doi. org/10.1016/j.apnr.2017.11.004

Dhiman, N., \& Arora, N. (2018). Exploring the relationship of PsyCap and turnover intentions: A study among health professionals. Amity Business Review, 19(1) 106-118.

Doherty, J., Gilson, L., \& Shung-King, M. (2018). Achievements and challenges in developing health leadership in South Africa: The experience of the Oliver Tambo Fellowship Programme 2008-2014. Health Policy and Planning, 33(2), 50-64. https://doi.org/10.1093/heapol/czx155

Du Plessis, M. (2014). The relationship between authentic leadership, psychological capital, followership and work engagement. Unpublished doctoral dissertation. Retrieved from http://hdl.handle.net/11394/3903

Du Plessis, M., \& Boshoff, A.B. (2018). The role of psychological capital in the relationship between authentic leadership and work engagement. South African Journal of Human Resource Management, 16(1), a1007, 9 pages. https://doi. Journal of Human Resource Mona
org/10.4102/sajhrm.v16i0.1007

Fallatah, F., Laschinger, H., \& Read, E. (2017). The effects of authentic leadership, organizational identification, and occupational coping self-efficacy on new graduate nurses' job turnover intentions in Canada. Nursing Outlook, 65(2), 172-183. https://doi.org/10.1016/j.outlook.2016.11.020

Gilmartin, M.J., \& D’Aunno, T.A. (2007). Leadership research in healthcare. The Academy of Management Annals, 1(1), 387-438. https://doi.org/10.1080/078559813

Gilson, L., \& Daire, J. (2011). Leadership and governance within the South African health system. South African Health Review, 69-80. Retrieved from http:// reference.sabinet.co.za/sa_epublication_article/healthr_2011_a8

Gravetter, F.J., \& Forzano, L.A. (2012). Research methods for behavioural sciences (4th edn.). Belmont, CA: Wadsworth Learning.

Griffeth, R.W., Hom, P.W., \& Gaertner, S. (2000). A meta-analysis of antecedents and correlations of employee turnover: Update, moderator tests, and research correlations of employee turnover: Update, moderator tests, and research
implications for the next millennium. Journal of Management, 26(3), 463-488. implications for the next millennium. Journal
https://doi.org/10.1177/014920630002600305

Guest, D.E., Isaksson, K., \& De Witte, H. (2010). Employment contracts, psychological contracts, and employee well-being: An international study. New York, NY: Oxford University Press.

Gupta, M., \& Shaheen, M. (2017). Impact of work engagement on turnover intention: Moderation by psychological capital in India. Business: Theory and Practice, 18(1) 136-143. https://doi.org/10.3846/btp.2017.014

Hayes, A.F. (2017). Introduction to meditation, moderation, and conditional process analysis (2nd edn.). New York, NY: Guilford Press.

Hayes, L.J., O'Brien-Pallas, L., Duffield, C., Shamian, J., Buchan, J., Hughes, F., ...North N. (2012). Nurse turnover: A literature review - An update. International Journal of International Nursing Studies, 49(7), 887-905. https://doi.org/10.1016/j. ijnurstu.2011.10.001
Health Systems Trust. (2018). South African Health review 2018. Retrieved from https://www.hst.org.za/publications/South\%20African $\% 20$ Health\%20Reviews/ SAHR\%202018.pdf

Hobfoll, S.E., Halbesleben, J., Neveu, J.-P., \& Westman, M. (2018). Conservation of resources in the organizational context: The reality of resources and their consequences. Annual Review of Organizational Psychology and Organizational Behavior, 5(1), 103-130. https://doi.org/10.1146/annurev-orgpsych-032117-104640

Hu, L., \& Bentler, P.M. (1999). Cut-off criteria for fit indexes in covariance structural analysis: Conventional criteria versus new alternative. Structural Equation modelling: A Multidisciplinary Journal, 6(1), 1-55. https://doi.org/10.1080/ 10705519909540118

Ilies, R., Morgeson, F.P., \& Nahrgang, J.D. (2005). Authentic leadership and eudaimonic well-being: Understanding leader-follower outcomes. The Leadership Quarterly, 16(3), 373-394. https://doi.org/10.1016/j.leaqua.2005.03.002

JASP Team. (2019). JASP version 0.11.1 [Computer software]. JASP. https://jasp-stats.org/

Kim, M., Kim, A.C.H., Newman, J.I., Ferris, G.R., \& Perrewé, P.L. (2019). The antecedents and consequences of positive organizational behavior: The role of psychological capital for promoting employee well-being in sport organizations. Sport Management Review, 22(1), 108-125. https://doi.org/10.1016/j.smr.2018.04.003

Kinsler, L. (2014). Born to be me...who am I again? The development of authentic leadership using evidence-based leadership coaching and mindfulness. International Coaching Psychology Review, 9(1), 92-105.

Kline, R.B. (2016). Principles and practice of structural equation modeling (4th edn.). New York, NY: The Guilford Press.

Koberg, C.S., Boss, R.W., Goodman, E.A., Boss, A.D., \& Monsen, E.W. (2005). Empirical evidence of organizational citizenship behaviour from the health care industry. International Journal of Public Administration, 28(5-6), 417-436. https://doi. International Journal of Public
org/10.1081/PAD-200055199

Kumar, R.D.C. (2013). Leadership in healthcare. Anaesthesia and Intensive Care Medicine, 14(1), 39-41. https://doi.org/10.1016/j.mpaic.2012.11.006

Laschinger, H.K.S., Cummings, G., Leiter, M., Wong, C., MacPhee, M., Ritchie, J. ...Read, E. (2016). Starting out: A time-lagged study of new graduate nurses' transition to practice. International Journal of Nursing Studies, 57(1), 82-95. https://doi. org/10.1016/j.ijnurstu.2016.01.005

Laschinger, H.K.S., \& Fida, R. (2014a). New nurses' burnout and wellbeing: The influence of authentic leadership and psychological capital. Burnout Research, 1(1), 19-28. https://doi.org/10.1016/j.burn.2014.03.002

Laschinger, H.K.S., \& Fida, R. (2014b). A time-lagged analysis of the effect of authentic leadership on workplace bullying, burnout, and occupational turnover intentions. European Journal of Work and Organizational Psychology, 23(5), 739-753. https://doi.org/10.1080/1359432X.2013.804646

Lee, H.F., Chiang, H.Y., \& Kuo, H.T. (2019). Relationship between authentic leadership and nurses' intent to leave: The mediating role of work environment and burnout. Journal of Nursing Management, 27(1), 52-65. https://doi.org/10.1111/ jonm.12648

Little, T.D., Rhemtulla, M., Gibson, K., \& Schoemann, A.M. (2013). Why the items versus parcels controversy needn't be one. Psychological Methods, 18(3) 285-300. https://doi.org/10.1037/a0033266

Luthans, F. (2002). The need and meaning for positive organisational behavior. Journal of Organizational Behavior, 23(6), 695-706. https://doi.org/10.1002/job.165

Luthans, F., \& Avolio, B.J. (2003). Authentic leadership: A positive developmental approach. In K.S. Cameron, J.E. Dutton, \& R.E. Quinn (Eds.), Positive organizational
scholarship: Foundations of a new discipline (pp. 241-261). San Francisco, CA: scholarship: Foundations of

Luthans, F., Avolio, B.J., Avey, J.B., \& Norman, S.M. (2007). Positive psychological capital: Measurement and relationship with performance and satisfaction. Personnel Measurement and relationship with performance and satisfaction. Personn
Psychology, 60(3), 541-572. https://doi.org/10.1111/j.1744-6570.2007.00083.x

Luthans, F., Luthans, K.W., \& Luthans, B.C. (2004). Positive psychological capital: Beyond human and social capital. Business Horizons, 47(1), 45-50. https://doi. org/10.1016/j.bushor.2003.11.007

Luthans, F., \& Youssef-Morgan, C.M. (2017). Psychological capital: An evidence-based positive approach. Annual Review of Organizational Psychology and Organizational Behavior, 4(1), 339-366. https://doi.org/10.1146/annurevorgpsych-032516-113324

Luthans, F., Youssef-Morgan, C.M., \& Avolio, B. (2015). Psychological capital and beyond. New York, NY: Oxford University Press.

Maldanado, M.L. (2013, February 27). How authentic is your leadership development? Chief Learning Officer. Retrieved from https://www.chieflearningofficer com/2013/02/27/how-authentic-is-your-leadership-development/

Malila, N., Lunkka, N., \& Suhonen, M. (2018). Authentic leadership in healthcare: A scoping review. Leadership in Health Services, 31(1), 129-146. https://doi. org/10.1108/LHS-02-2017-0007

Maloney, W., Boxall, P., Parsons, M., \& Cheung, G. (2018). Factors predicting registered nurses' intentions to leave their organization and profession: A job demandsresources framework. Journal of Advanced Nursing, 74(4), 864-875. https://doi. org/10.1111/jan.13497

Maphumulo, W.T., \& Bhengu, B.R. (2019). Challenges of quality improvement in the healthcare of South Africa post-apartheid: A critical review. Curationis, 42(1), a1901. https://doi.org/10.4102/curationis.v42i1.1901

Munyaka, S.A. (2012). The relationship between authentic leadership, psychological capital, psychological climate, team commitment and the intention to quit in a South African manufacturing organisation. Doctoral dissertation. Port Elizabeth: Nelson Mandela Metropolitan University. Retrieved from https://core.ac.uk/ download/pdf/145050504.pdf 
Munyaka, S.A., Boshoff, A.B., Pietersen, J., \& Snelgar, R. (2017). The relationship between authentic leadership, psychological capital, psychological climate, team commitment and intention to quit. South African Journal of Industrial Psychology, 43(0), a1430, 11 pages. https://doi.org/10.4102/sajip.v43i0.1430

Muthén, B.O., \& Muthén, L.M. (1998-2018). Mplus (Version 8.4). Computer software. Los Angeles, CA: Muthén \& Muthén.

Neider, L.L., \& Schriesheim, C.A. (2011). The Authentic Leadership Inventory (ALI) Development and empirical tests. The Leadership Quarterly, 22(6), 1146-1164. https://doi.org/10.1016/j.leaqua.2011.09.008

Newman, A., Ucbasaran, D., Zhu, F., \& Hirst, G. (2014). Psychological capital: A review and synthesis. Journal of Organizational Behavior, 35(1), 120-138. https://doi. org/10.1002/job.1916

Organ, D.W. (1988). Organizational citizenship behavior: The good soldier syndrome. Lexington, MA: Lexington Books.

Organ, D.W. (1997). Organizational citizenship behaviour: It's construct clean-up time. Human Performance, 10(2), 85-97. https://doi.org/10.1207/s15327043hup1002_2

Perreira, T.A., \& Berta, W. (2016). The object of your affection: How commitment leadership and justice influence workplace behaviours in health care. Journal of Nursing Management, 24(2), 146-154. https://doi.org/10.1111/jonm.12316

Podsakoff, N.P., LePine, J.A., \& LePine, M.A. (2007). Differential challenge stressorhindrance stressor relationships with job attitudes, turnover intentions, and withdrawal behaviour: A meta-analysis. Journal of Applied Psychology, 92(2), 438-454. https://doi.org/10.1037/0021-9010.92.2.438

Podsakoff, P.M., Mackenzie, S.B., Lee, J.-Y., \& Podsakoff, N.P. (2003). Common method biases in behavioural research: A critical review of the literature recommended remedies. Journal of Applied Psychology, 88(1), 879-903. https://doi. org/10.1037/0021-9010.88.5.879

Podsakoff, N.P., Podsakoff, P.M., Mackenzie, S.B., Maynes, T.D., \& Spoelma, T.M. (2014). Consequences of unit-level organizational citizenship behaviors: A review and recommendations for future research. Journal of Organizational Behavior 35(1), 87-119. https://doi.org/10.1002/job.1911

Rego, A., Sousa, F., Marques, C., \& Cunha, M.P. (2012). Authentic leadership promoting employees' psychological capital and creativity. Journal of Business Research, 65(3), 429-437. https://doi.org/10.1016./j.jbusres.201110.003

Revelle, W., \& Zinbarg, R.E. (2009). Coefficients Alpha, Beta, Omega, and the glb: Comments on Sijtsma. Psychometrika, 74(1), 145-154. https://doi.org/10.1007/ s11336-008-9102-z

Ritter, D. (2011). The relationship between healthy work environments and retention of nurses in a hospital setting. Journal of Nursing Management, 19(1), 27-32. https://doi.org/10.1111/j.1365-2834.2010.01183.x

Rothmann, S. (2010). The reliability and validity of measuring instruments of happiness in the Southern African context. Unpublished research report. Vanderbijlpark: North-West University.

Sasso, L., Bagnasco, A., Catania, G., Zanini, M., Aleo, G., Watson, R., \& RN4CAST@IT Working Group. (2019). Push and pull factors of nurses' intention to leave. Journal of Nursing Management, 27(5), 946-954. https://doi.org/10.1111/jonm.12745

Selamat, N., Nordin, N., \& Fook, C.Y. (2017). Organisational justice and organisational citizenship behaviour: Evidence from a developing country. Global Business \& Management Research, 9(1), 383-392.

Shapira-Lishinsky, O., \& Tsemach, S. (2014). Psychological empowerment as a mediator between teachers' perceptions of authentic leadership and their withdrawal and citizenship behaviours. Educational Administration Quarterly, 50(4), 675-712. https://doi.org/10.1177/0013161X13513898
Shisana, O. (2018, October 19). Strengthening the South African health system towards an integrated and unified health system. Paper presented at the Presidential Health Summit 2018, Johannesburg.

Smith, C.A., Organ, D.W., \& Near, J.P. (1983). Organizational citizenship behavior: Its nature and antecedents. Journal of Applied Psychology, 68(4), 653-663. https:// doi.org/10.1037/0021-9010.68.4.653

Spector, P.E. (2019). Do not cross me: Optimizing the use of cross-sectional designs. Journal of Business and Psychology, 34(1), 125-137. https://doi.org/10.1007/ s10869-018-09613-8

Stander, F.W., De Beer, L.T., \& Stander, M.W. (2015). Authentic leadership as source of optimism, trust in the organisation and work engagement in the public health care sector. South African Journal of Human Resource Management, 13(1), a675, 12 pages. https://doi.org/10.4102/sajhrm.v13i1.675

Tett, R.P., \& Meyer, J.P. (1993). Job satisfaction, organizational commitment, turnover intention, and turnover: Path analyses based on meta-analytic findings. Personne Psychology, 46(2), 259-293. https://doi.org/10.1111/j.1744-6570.1993.tb00874.x

Trinchero, E., Borgonovi, E., \& Farr-Wharton, B. (2014). Leader-member exchange, affective commitment, engagement, wellbeing, and intention to leave: Public versus private sector Italian nurses. Public Money and Management, 34(6), 38-388. https://doi.org/10.1080/09540962.2014.962361

Valsania, E.S., Léon, M.J.A., Alosono, M.F., \& Cantisano, T.G. (2012). Authentic leadership and its effect on employees' organizational citizenship behaviours. Psicothema, 24(4), 561-566.

Van Veldhoven, M., Van den Broeck, A., Daniels, K., Bakker, A.B., Tavares, S.M., \& Ogbonnaya, C. (2020). Challenging the universality of job resources: Why, when, and for whom are they beneficial? Applied Psychology: An International Review, 69(1), 5-29. https://doi.org/10.1111/apps.12211

Walumbwa, F.O., Avolio, B.J., Gardner, W.L., Wernsing, T.S., \& Peterson, S.J. (2008). Authentic leadership: Development and validation of a theory-based measure. Journal of Management, 34(1),89-126. https://doi.org/10.1177/0149206307308913

Wang, H.U.I., Sui, Y., Luthans, F., Wang, D., \& Wu, Y. (2014). Impact of authentic leadership on performance: Role of followers' positive psychological capital and relational processes. Journal of Organizational Behavior, 35(1), 5-21. https://doi. org/10.1002/job.1850

Wang, J., \& Wang, X. (2020). Structural equation modelling (2nd edn.). Chichester: Wiley \& Sons Inc.

West, S.G., Taylor, A.B., \& Wu, W. (2012). Model fit and model selection in structura equation modeling. In R.H. Hoyle (Ed.), Handbook of structural equation modeling (pp. 209-231). New York, NY: The Guilford Press.

Winterton, J. (2004). A conceptual model of labour turnover and retention. Human Resources Development International, 7(3), 371-390. https://doi. org/10.1080/1367886042000201967

Woolley, L., Caza, A., \& Levy, L. (2014). Authentic leadership and follower development: Psychological capital, positive work climate, and gender. Journal of Leadership \& OrganizationalStudies, 18(4), 438-448. https://doi.org/10.1177/1548051810382013

World Health Organization. (2013). The world health report: Research for universal health coverage. Retrieved from http://www.who.int/whr/2013/report/en/

Wu, W.Y., \& Nguyen, K.H. (2019). The antecedents and consequences of psychological capital: A meta-analytic approach. Leadership \& Organization Development Journal, 40(4), 435-456. https://doi.org/10.1108/LODJ-06-2018-0233

Youssef-Morgan, C.M., \& Petersen, K. (2019). The benefits of developing psychological capital in the workplace. In R. Burke \& A. Richardson (Eds.), Creating psychologically healthy workplaces (pp. 113-132). Cheltenham: Edward Elgar Publishing. 